\title{
Uma leitura particular das conexões de Freud com a Educação
}

\author{
Luisa Puricelli Pires \\ Rose Gurski*
}

Resumo: Através de fragmentos de textos freudianos que tratam das relações entre Psicanálise e Educação, propomos uma leitura particular desta conexão. Traçamos um percorrido investigativo guiado pelo desejo de Freud em enlaçar os efeitos da Psicanálise às questões culturais de seu tempo. Neste diapasão, sublinhamos seu intenso interesse pelo diálogo com a Educação como um enigma deixado pela sua transmissão às futuras gerações. Este desejo, ainda hoje, possibilita potentes efeitos de criação de novos sentidos a partir de experiências atuais nos diálogos entre os dois campos.

Palavras-chave: Educação. Psicanálise. Freud. Cultura.

\section{A Particular Reading of Freud's Connections with Education}

Abstract: Through a few fragments of Freudian texts that deal with the relations between psychoanalysis and education, we propose a particular reading of this connection. We have traced a research trail guided by Freud's desire to link the effects of Psychoanalysis to the cultural issues of his time. In this context, we underline his intense interest in the dialogue with Education, as an enigma left by his transmission to future generations. Until today, this desire produces powerful effects that allow us to create new meanings from current experiences in the dialogues between both fields.

Keywords: Education. Psychoanalysis. Freud. Culture

A chegada da Psicanálise na Viena vitoriana, do início do século XX, pelas mãos de um médico judeu foi motivo de muita tensão e de muitos paradoxos; se alguns a festejavam como uma nova ciência capaz de desdobrar enigmas do sofrimento humano, não faltaram adversários confessos que desdenhavam de qualquer possibilidade de que seus pressupostos pudessem representar um avanço na decifração dos mistérios da alma.

Sigmund Freud, nascido Sigismund, era o primogênito de sua mãe e o terceiro filho de seu pai, que, já tinha sido casado anteriormente, dando ao pequeno Freud dois irmãos mais velhos. Nessa configuração familiar, com toques de "modernidade", Freud teve sempre um lugar de destaque, principalmente no que se refere ao laço com o saber. Contam alguns biógrafos que, em seus momentos

\footnotetext{
* Psicanalista associada ao Centro de Estudos Psicanalíticos de Porto Alegre (CEPdePA) e Bolsista CAPES no Mestrado do Programa de Pós-Graduação (PPG) em Psicanálise: Clínica e Cultura da Universidade Federal do Rio Grande do Sul (UFRGS). E-mail: luisa_puricelli@yahoo.com.br

** Professora e Vice Coordenadora do PPG Psicanálise: Clínica e Cultura (UFRGS); Coordenadora do Curso de Especialização Intervenção Psicanalítica na Clínica com Crianças e Adolescentes (IP-UFRGS); Psicanalista; membro da Associação Psicanalítica de Porto Alegre (APPOA); Doutora em Educação pela UFRGS; Co-coordenadora do Núcleo de Pesquisa em Psicanálise, Educação e Cultura (NUPPEC/UFRGS); autora de Três ensaios sobre juventude e violência (Escuta, 2012).E-mail: rosegurski@ufrgs.br.
}

\begin{tabular}{|l|l|l|l|l|l} 
APRENDER - Cad. de Filosofia e Psic. da Educação & Vitória da Conquista & Ano XI & n. 17 & p. 11-23 & jan./jun.2017 \\
\hline
\end{tabular}


de estudo, as irmãs tinham de fazer absoluto silêncio a fim de que Sig, como era chamado carinhosamente pela mãe, tivesse condições ótimas de aprendizagem (GAY, 2012).

O jovem Freud sorveu uma educação clássica e primorosa, mantendo-se um ávido leitor durante toda a vida, o que contribuiu muito com a vocação investigativa que apresentava, tanto do ponto de vista clínico, quanto teórico. Todo este investimento não foi em vão, Freud soube utilizar, com muita desenvoltura, os conhecimentos relativos tanto às contribuições das ciências naturais ${ }^{1}$, quanto às produções das ciências do espírito, através de excertos de mitos, poesias, romances. Através, também, do recolhimento de contribuições de outras áreas, soube dar musculatura às suas descobertas e construções (SCHUR, 1981).

Freud era também conhecido como Herr Professor, nunca escondendo a estima por essa posição, inclusive mantendo viva e declarada a vontade de tornar-se um catedrático na Universidade. Este lugar de reconhecimento acadêmico, que lhe foi negado, não só pelas resistências atávicas ao movimento psicanalítico, mas, também, por várias circunstâncias sociais e políticas da Viena e da Europa da primeira metade do século XX, parece ter recebido um ajuste da história em nosso tempo social. No Brasil, por exemplo, além da Psicanálise estar presente nas disciplinas da graduação, as Universidades já contam com Programas de Pós-graduação, cujas pesquisas tem no método psicanalítico sua principal ferramenta de investigação.

É importante sublinhar que o próprio Freud declarava seu pouco investimento na direção dos diálogos com a Educação, como aparece neste fragmento das Novas Conferências Introdutórias de Psicanálise:

[...] Apenas um tema eu não posso evitar assim facilmente, não porque entenda bastante ou tenha contribuído muito para ele. Pelo contrário, quase não me ocupei dele. Mas é tão importante, tão rico de esperanças para o futuro, que talvez seja o trabalho mais relevante da psicanálise. Falo de sua aplicação à pedagogia, à educação da próxima geração (FREUD, 1933/2006, p. 307).

De todo modo, apesar do reconhecimento explícito que fazia a respeito de alguma negligência com o campo, nunca deixou de assinalar sua crença de que este diálogo poderia ser muito potente para o futuro da Psicanálise. Recolhemos, então, algumas nuances do "mestre" Freud, justamente para que possamos abrir nosso diálogo com o campo da Educação. Assim, em "contrapelo" às afirmações acerca de seu pouco investimento no laço com a educação, buscamos realizar, neste escrito, uma leitura particular desta conexão, considerando desde a sua própria formação educativa, pertencendo à tradição do povo do livro, até às construções na direção de uma certa aplicação da Psicanálise à Educação.

\footnotetext{
1 Segundo Mezan (2014, p. 551) "foi o filósofo Wilhelm Dilthey, em sua Introdução às ciências do espírito, de 1883, que sistematizou esta oposição [...]” entre ciência do espírito e da natureza.
} 


\section{A Psicanálise entre a terapêutica e a cultura: do grão à pérola}

De forma geral, vemos, na história da Psicanálise, como Freud se ressentia do meio médico por este não dar o justo valor que ele atribuía à invenção da Psicanálise. Sentia-se diminuído, excluído e relegado a uma segunda classe de médicos. Em suas cartas a Fliess, lemos claramente sua desmotivação em inúmeros momentos do início de sua empreitada (FREUD, 1893/2006).

Nos primeiros anos do século XX, logo após a Interpretação dos Sonhos² ${ }^{2}$ Freud (1900/2006) conseguiu reunir ao seu redor um grupo de intelectuais, artistas e simpatizantes, que, enquanto pioneiros, foram denominados como o grupo da Sociedade Psicológica das Quartas-feiras. Era impressionante a potência transferencial de Herr Professor, "um enigma que surgia na mente de Freud era como um corpo estranho, o grão de areia na ostra que não pode ser ignorado e que, ao final, pode resultar em uma pérola”, como bem assinala Peter Gay (2012, p. 321).

Podemos conjecturar que o "amor ao saber", que transbordava nas transmissões freudianas, foi responsável por forjar um dos traços de maior distinção da sua personalidade: a tenaz posição investigativa, tarefa da qual Freud nunca recuou. Nas palavras de Ernest Jones, as fortes expectativas que tiveram origem nos anseios familiares acerca de seu futuro, levaram Freud a estabelecer para si um compromisso com a busca da compreensão por tudo aquilo que se apresentava como um enigma (GAY, 2012). Assim, se, por um lado, identificamos algumas das variáveis pessoais que levaram o jovem Freud a insistir com a invenção de uma nova ciência, por outro, para fins deste escrito, também interessa entendermos as variáveis sociais, políticas e culturais que o levaram aos diálogos com o campo da Educação.

Ressaltamos que, desde os primórdios, Freud tentava operar uma leitura psicanalítica também fora da clínica, prestando atenção às manifestações do inconsciente no social, na leitura dos fenômenos e dos sintomas da cultura. O tema da cultura e sua função subjetivante aparecem já no texto do Projeto, em 1895, através do complexo do próximo (FUKS, 2007), e segue com sucessivas elaborações até 1921, no texto visionário sobre a psicologia das massas, em que Freud vai sublinhar a famosa definição de que toda psicologia individual é também um modo de psicologia social ${ }^{3}$.

É nesse sentido que podemos pensar que o interesse pela educação talvez tenha se dado justamente como um efeito de seu interesse pela cultura, pois ambos os campos são constitutivos do sujeito, já que pertencem ao que se denomina campo do discurso do Outro. Como diz Kupfer (2007, p.35), "o ato de educar é o ato pelo meio do qual o Outro se intromete na carne do infans". Esta nos

\footnotetext{
2 Texto de 1900, a Interpretação dos Sonhos configura-se como o escrito mais longo e de mais amplo alcance da obra freudiana.

${ }^{3}$ Ver cap. 7 da conhecida Psicologia das massas e análise do eu (FREUD, 1921/2012).
} 
parece ser a concepção de Educação que dá início ao diálogo com a Psicanálise, pois é central para a visão psicanalítica de sujeito ${ }^{4}$.

Encontramos uma clara enunciação de Freud quanto ao seu amor pelas causas da cultura, no que se refere à subjetividade, no texto Um estudo autobiográfico (1925/2006). Contudo, sua aposta na direção de que as aplicações à Educação poderiam render muitas pérolas à construção do lugar da Psicanálise no social data de antes. Já no início do século XX, por volta de 1910, Freud não escondia a vontade de expansão da Psicanálise e, para tanto, apostava que a Educação poderia ser um campo de grande retorno para o movimento psicanalítico.

Tal aposta não deixava de ter uma relação com as transferências de Freud. Segundo Voltolini (2011), inspirando-se na "Estrutura das revoluções científicas" de Thomas Mann, às vezes importa mais o drama que envolve o contexto dos conceitos, do que propriamente sua trama. Em $A$ história do movimento psicanalítico, Freud (1914/2006) relata como teve de sustentar sozinho a Psicanálise durante anos, pois faltava-lhe parceiros que apostassem nessa nova forma de escutar o sofrimento humano. Seu afã científico inscrevia um novo saber na cultura efervescente da Viena do início do século XX, em que objeto e método de investigação se equivaliam. Só se poderia estudar o inconsciente com ferramentas que fizessem ponte aos modos de funcionamento deste: nesta esteira de questões, surgiram os conceitos de atenção flutuante, do a posteriori e da transferência.

Porge (2009) trará a ideia de que Freud inaugura, para além da Psicanálise, enquanto meio de tratamento, um modo de transmitir o saber inconsciente. Relatando o caso clínico em outra temporalidade, que não a médica, estabeleceu-se uma forma romanceada de fazer o material clínico falar, em que Freud escutou não apenas o inconsciente da experiência com os pacientes, mas seu desejo pela escrita clássica transformado na inscrição de um novo lugar. Constituindo-se enquanto psicanalista, parece que Freud inova sua leitura dos clássicos, fazendo seu o que herdara dos mestres ${ }^{5}$.

Neste aspecto, entende-se um pouco o que levou Freud a expressar, em mais de um momento, o desejo de que a Psicanálise estivesse próxima de outras áreas, meio pelo qual acreditava que a ciência se manteria pulsante (FREUD, 1914/2006). Talvez a própria ampliação do interesse pelas ciências do espírito também ocorria devido à distância, cada vez maior, da medicina. Esta inclinação aparece de forma muito vívida no texto de 1913, Interesses da Psicanálise, no qual Freud apresenta a nova ciência a um público douto, apontando os princípios fundamentais da Psicanálise, especialmente o modo como ela poderia servir a outros ramos do conhecimento ${ }^{6}$ (FREUD, 1911-1913/2012).

\footnotetext{
4 Tal noção inaugura aquilo que, mais tarde, Lacan irá denominar de êxtimo, o que é o mais íntimo do sujeito e se encontra fora dele (LACAN, 1959-1960/2010).

${ }^{5}$ Goethe é um desses mestres a quem Freud faz referência inúmeras vezes em suas cartas e em alguns de seus textos, relação marcada fortemente no discurso proferido quando da entrega do Prêmio Goethe a ele, em 1930 (FREUD, 1930/2006).

${ }^{6}$ Este texto foi publicado originalmente, em 1913, na Revista Scientia (v. 14, n. 31, p. 240-250) - uma revista italiana que reunia contribuições científicas vindas de vários países europeus. A editoria solicitou a Freud a escrita das principais afirmações da Psicanálise. Sublinhamos a importância deste escrito, pois Freud apresentou nele algumas questões epistemológicas da Psicanálise. Além de realizar certa apresentação de alguns fundamentos, comentou as possíveis
} 
Quando Freud sugeriu a possibilidade de uma educação psicanaliticamente orientada, estava também interessado em duas questões. Uma era de que a Psicanálise pudesse trilhar novos horizontes em que gozasse de melhor reputação, dada a resistência que o meio médico lhe conferia, e outra dizia respeito à expansão para além do meio judaico de Viena. Assim lhe agradava as companhias dos suíços, o pastor Oskar Pfister, Hans Zulliger e Carl Gustav Jung. Todos os três, além de Frenczi e Abraham, passaram a fazer parte, em 1907, da primeira instituição psicanalítica, a Sociedade Psicanalítica de Viena (GAY, 2012).

De modo bastante particular, há uma forte produção, principalmente entre os anos de 1909 e 1913 e depois, de 1925 a 1926, que evidencia uma franca esperança de Freud em ver a Psicanálise na cultura através da Educação. Vejamos de que modo o vienense apostava que destes grãos pudesse advir uma pérola.

\section{O aluno e a figura do professor: a sexualidade infantil e juvenil}

Em Algumas Reflexões sobre a Psicologia Escolar de 1914, Freud retrata, de forma autobiográfica, a importância que a figura dos professores teve em sua vida, evidenciando que, mesmo adulto, qualquer pessoa se sente impelida a corresponder à demanda de um professor, obedecendo ordens, respondendo a questões, enfim, se sentindo avaliado como se uma criança fosse. Confessando as marcas que essa experiência lhe deixara, ele comenta os sentimentos despertados por uma lembrança a respeito da monografia que fez ao final do percurso escolar, em que sonhava realizar um grande feito, reconhecido socialmente, quando se tornasse adulto (FREUD, 1914b/2006).

Compreendendo que o papel da escola seria levar os jovens a desejar estudar, direcionando sua libido antes voltada primordialmente para as questões da sexualidade infantil, para o conhecimento, Freud (1914b/2006, p. 243) assevera que "é difícil dizer se o que exerceu mais influência sobre nós e teve importância maior foi a nossa preocupação pelas ciências que nos eram ensinadas, ou pela personalidade de nossos mestres". Apresentando de forma bastante direta as influências que essas figuras causam nos jovens, sublinha os efeitos que ainda sentia em si mesmo, quando se encontrava com nuances de um passado retratado em memórias de infância.

Através da noção de ambivalência, Freud (1914b/2006) afirma que a relação com os professores é intensa, mobilizando sentimentos de amor e de ódio, crítica e respeito, em face da ânsia de identificar-se com eles, em que o sujeito forma e deforma seu caráter a partir do que pressupõe neles. Pensando em uma posição de submissão que o sujeito fica perante a figura do professor, essa

contribuições da nova ciência para outros ramos do conhecimento, dentre eles, a linguagem, a filosofia, história da evolução estética e a pedagogia, entre outros. A indicação da Revista Scientia consta na abertura do texto O Interesse da Psicanálise das obras completas. Consultas, conforme a bibliografia (FREUD, 1913/2012). 
“espécie de herança emocional” parece traduzir-se em Freud (1914b/2006, p. 245) em uma narrativa que versa sobre a própria experiência educacional.

Buscando fragmentos nos quais Freud falara das origens dessa relação tão intensa que ocorre na escola, fomos percebendo que tais colocações percorrem toda a sua obra, caracterizando-se por, na maioria das vezes, estarem em pequenas passagens dos textos, o que nos possibilitou ir fazendo uma costura dessas ideias.

Freud (1905/2006, p.192) aponta em Três Ensaios para a Teoria da Sexualidade, que "o comportamento das crianças na escola, que propõe aos professores um número bastante grande de enigmas, merece, em geral, ser relacionado com o desabrochar de sua sexualidade". Afirmando que a pulsão sexual está presente nas crianças, Freud evidencia o processo de formulação de fantasias que tentam responder à curiosidade natural que lhes toma a respeito da vida dos adultos, do nascimento de bebês e da diferença sexual entre meninos e meninas. Esse movimento psíquico evidencia o início de uma posição de investigação e interesse intelectual, que se debruça sobre os enigmas do sexual e, mais tarde, sobre o mundo e suas relações.

Nesse sentido, nos primeiros anos do início do século XX, Freud advoga que o esclarecimento sexual das crianças deveria se dar de forma natural, atrelando-se ao processo de aprendizagem e relacionando-se aos efeitos físicos e sociais da sexualidade. Nessa perspectiva, Freud (1913b/2012) chega a mencionar que a escola teria uma responsabilidade profilática, em que se pouparia a criança de futuras neuroses e perversões ao apresentar uma postura aberta em relação a sua curiosidade sexual; o educador poderia, assim, determinar quais disposições prejudicariam a criança no futuro, aplicando os conhecimentos da Psicanálise antecipadamente, a fim de conduzi-la a um fim desejável. Dessa maneira, se evitaria a crescente desconfiança e decepção da criança com os adultos quando ela, mais cedo ou mais tarde, percebe que estes the mentiram acerca do sexual (FREUD, 1907/2006).

Ampliando suas contribuições, anos depois, em $O$ ego e o id, Freud (1923/2006) expõe como o papel do professor está relacionado com a formação do ideal de ego na criança, conceito que será importante em sua obra inclusive para a compreensão do mecanismo de Recalque, que para ele tem função socializadora.

Nesse sentido, portanto, as vivências infantis que ficaram conhecidas por serem responsáveis pela constituição psíquica dos sujeitos e de seus modos de se relacionarem e se inserirem no laço social ganham novo espaço de expressão na escola. Essa saída do espaço familiar para o espaço social marca um processo de repetição do padrão relacional, como Freud salienta nestes trechos, em que o sujeito vê no professor a figura paterna, evidenciando o tanto de assujeitamento que está contido nesse caminho. Essa referência moral se instala no superego, instância julgadora e controladora do ego (FREUD, 1924/2006).

O sentimento de culpa provindo destas vivências infantis precoces, em que o sujeito teve de abater uma parcela de suas satisfações libidinais para assimilar outros meios de obter prazer, impeliram 
os sujeitos a sentimentos pró-sociais, possibilitando-os conviver em sociedade. Se colocando em consonância com outros egos, mantendo um ideal comum que propulsiona o movimento de social e, ao mesmo tempo, incapacita a formulação de novas posições e saberes, restringindo sua ação no mundo (FREUD, 1921/2012; 1930/2006).

Freud (1910/2006) chegou a nomear isso de forma bastante drástica em um texto pouco conhecido no meio psicanalítico que fora apresentado em um congresso sob o título Contribuições para uma Discussão acerca do Suicídio. Neste escrito, Freud (1910/2006, p. 243) coloca que a escola "deve conseguir mais do que não impelir seus educandos ao suicídio. Ela deve lhes apresentar o desejo de viver, oferecer-lhes apoio e amparo numa época da vida em que as condições de seu desenvolvimento os compelem a afrouxar seus vínculos com a casa dos pais e com a família". Se, por um lado, Freud achava que a escola deveria controlar os sujeitos e ajudá-los a acalmar os impulsos libidinosos, por outro, sustentava que a escola deveria dar espaço e tempo aos jovens para que pudessem usufruir de sua passagem pela infância e pela adolescência, demorando-se nessas vivências tanto quanto se fizesse necessário.

\section{Da profilaxia à transferência: a empatia pelo infantil}

Inicialmente, Freud via a relação da Psicanálise com a Educação como um modo de profilaxia dos sofrimentos psíquicos, no sentido de apostar que a não repressão sexual provinda das figuras fundamentais, pais e professores, fosse um modo de garantir uma certa normalização das crianças, as quais não passariam a desenvolver uma "patologia" psíquica.

Em 1926, quando (1926/2006) escreve A questão da análise Leiga: conversações com uma pessoa imparcial - tendo como pano de fundo o processo jurídico sofrido por Theodor Reiki, um de seus discípulos mais fiéis que fora acusado de charlatanismo pelo exercício ilegal da medicina -, Freud segue as argumentações em defesa da análise conduzida por não médicos, defesa que, de algum modo, já havia iniciado a argumentação em 1913, quando produziu o Prefácio a "O método Psicanalítico de Oskar Pfister" (FREUD, 1926/2006; 1913b/2012).

Nessa mesma linha, Freud (1940/2006), em Esboço de Psicanálise, discute nuances do trabalho do analista -, ponto no qual, muitas vezes antes, deixara lacunas em seus textos- levando muitos de seus leitores a considerar a posição do analista próxima a de um educador ou um pós-educador, como chega mesmo a afirmar no prefácio ao livro de Pfister (FREUD, 1913b/2012). Neste mesmo escrito, Freud dirá que o educador ou seu equivalente nos países protestantes, o pastor, tem muito mais condição de lidar com os sintomas da criança do que o médico.

A transferência, ponto que passa a ser nodal para a práxis psicanalítica, marca a repetição das vivências dos sujeitos em épocas primordiais da infância, em que a libido que um dia foi destinada 
diretamente aos pais, primeiro objeto de amor da criança, e aos mestres, seus substitutos mais diretos, insiste em retornar com força extrema. O passado se faz presente, sendo direcionado para figuras da vida atual da pessoa, porém com base nos padrões de relação criados na infância (FREUD, 1912/2006).

$\mathrm{Na}$ análise, a posição de abstinência do psicanalista fica bem evidente, à medida que Freud (1940/2006) propõe a diferença entre a posição do analista e do educador que, em posição de mestria, submete o outro, repetindo um estereótipo da relação parental. Pensando a formação do educador em Psicanálise, Freud (1913b/2012) havia afirmado que este não enfrentaria problemas, tendo em vista que o saber psicanalítico se distancia do saber da medicina. Trabalhando com a ideia de que professores, e educadores de modo geral, têm grande influência sobre os jovens, Freud sublinha que, mesmo eles, não devem impor seus ideais aos educandos, mas trabalhar com as possibilidades demonstradas por estes (FREUD, 1913b/2012).

Em 1925, ao escrever o Prefácio a Juventude Desorientada, de August Aichhorn, Freud amplia o diálogo com a Educação através da experiência do educador e psicanalista austríaco, que se dedicou aos jovens delinquentes, como eram nomeados. Aichhorn dirigiu a Instituição OberHollabrunn, em Viena, trabalhando com um grupo de educadores que trabalhavam com os estes jovens-, atividade que atualmente denominamos de agentes socioeducadores ${ }^{7}$-, através da escuta da transferência.

Neste Prefácio, Freud (1925/2006) pontuou que, dentre as aplicações da Psicanálise, nenhuma produziu tanto interesse quanto a relação com a Educação e, em forma de gracejo, revelou que analisar e educar estariam entre as três profissões impossíveis, lado a lado com governar - retomando uma noção trazida por $\mathrm{Kant}^{8}$. Nesse texto, Freud pondera novamente, como fizera no prefácio ao livro de Pfister, que o educador deve passar por uma formação psicanalítica para que a criança não lhe fique como um estranho e, por fim, constata que a melhor instrução psicanalítica é a análise pessoal do educador.

Para além dessas constatações, considera que a Educação é sui generis e não pode ser confundida com a análise e nem substituída por ela. Nesses mesmos termos, a análise infantil pode ser usada como um recurso aos casos de sofrimento psíquico, mas não substituir a Educação. Freud (1925/2006) aponta que a relação entre Psicanálise e Educação teria que ser melhor estudada no futuro, deixando para todos nós o trabalho de fazer essas costuras a partir de nossas experiências com o campo.

\footnotetext{
${ }^{7}$ Com a construção das diretrizes que regulam a ação socioeducativa do Estado (BRASIL, 2014) com os jovens em conflito com a lei, passou-se a nomear os até então monitores como agentes socioeducativos, em uma referência que nos parece relembrar, em um paradoxo, tanto a relação com a educação, quanto com o sistema penitenciário.

${ }^{8}$ Conforme Voltolini (2011, p. 27), a frase original que inspirou o aforismo freudiano acerca das 3 profissões impossíveis “[...] é de Kant, expressa na Crítica da Razão Pura. Freud apenas adicionou o curar ao governar e ao educar, já destacados por Kant".
} 
Após a virada de 1920, quando Freud escreve Além do Princípio do Prazer, fica evidente o passo que é dado na teoria psicanalítica no sentido de se ter claro que a pulsão de morte ${ }^{9}$ não pode ser eliminada, ficando, assim, soterrada qualquer ideia de profilaxia a partir da Psicanálise. Entre as Novas Conferências, a intitulada Explicações, Aplicações e Orientações evidencia a construção que Freud (1933/2006) realizou no decorrer dos anos acerca da impossibilidade dessa espécie de higienização dos sujeitos, inserindo uma outra visão acerca do papel da escola frente aos anseios libidinosos das crianças e jovens e aos ideias do mundo adulto. Ora, se a escola deve reprimir o desejo sexual e fazer com que o sujeito aprenda a controlar suas pulsões, incluindo-o na Ordem Social, a Educação poderia estar à serviço da edificação da neurose.

Lajonquière, ao analisar os efeitos políticos, sociais e religiosos à época de Freud, resume bem essa passagem de uma Psicanálise voltada à profilaxia do sexual para um posterior distanciamento desta posição. Ele diz, em Sigmund Freud, a Educação e as crianças que "na contramaré das aparências de um 'primeiro Freud', encontramos uma reflexão sobre a irredutibilidade estrutural do desprazer psíquico e, portanto, da impertinência de pretender encontrar uma dosagem melhor das restrições civilizadoras" (LAJONQUIÈRE, 2002, p. 118).

O tema da análise com crianças, em alguns momentos, misturou-se com a educação de modo que a aplicação da Psicanálise à Educação e a análise infantil confundiram-se. Foi nas Novas Conferências que Freud (1933/2006) registrou sua esperança de que Anna, sua filha, pudesse reparar sua negligência com este campo, já que ele próprio não teria se dedicado muito ao tema.

Após os primórdios iniciais da Psicanálise com crianças, destacaram-se neste âmbito, Anna Freud e Melanie Klein. Ambas foram protagonistas de intensas controvérsias no domínio da técnica com crianças ocorridas entre 1925 e 1926. Para Anna Freud, a criança não poderia entrar em transferência com um analista, devido à impossibilidade de direcionar sua libido para outros adultos que não seus pais - o que se mostrou, aos longos dos anos, um impasse teórico bastante comprometedor, intensificando a noção de uma profilaxia na Educação (CIFALI; IMBERT, 1999). Por sua vez, Melanie Klein apostou na ideia de adaptar a técnica psicanalítica descrita por Freud para o atendimento infantil, mantendo os pressupostos da transferência e da associação livre, levando os pequenos ao trabalho analítico através da experiência do brincar e da interpretação do jogo. Klein dava grande ênfase à fantasia infantil e à resistência em análise, de modo que ela é, ainda hoje, referência para os estudiosos da análise com crianças, tendo colaborado também para as primeiras noções da análise com psicóticos, que foram mais amplamente difundidas no meio psicanalítico até os anos 70. Em contrapartida, Klein foi fortemente criticada por menosprezar a ação do ambiente em suas teorias, valorizando desmedidamente o mundo intrapsíquico e se dirigindo às crianças de forma bastante direta em suas

\footnotetext{
${ }^{9}$ A pulsão de morte é coloca por Freud (1920/2006) como uma tendência do ser humano a voltar ao estado inorgânico, ao nada, ao momento anterior à vida. Só sabemos da pulsão de morte quando ela está entrelaçada com a de vida, sendo sua expressão máxima encontrada nos comportamentos destrutivos.
} 
intervenções, ainda permeada por uma necessidade de explicar os conteúdos psíquicos de seus pacientes a eles próprios (CIFALI; IMBERT, 1999; KLEIN, 1991).

Apesar destes impasses na direção do trabalho com crianças não terem tido um posicionamento explícito da parte de Freud, destacamos uma correspondência trocada em 1927, com Joan Rivière, na qual Freud refere a disputa conceitual entre Klein e sua filha, Anna. O interessante é que, apesar de algumas manifestações nas quais apoiou a filha, nesta correspondência especialmente, parece ter tomado a posição que lhe cabia. De modo salomônico disse que a experiência é que deveria ter a palavra final no que se referia ao verdadeiro estatuto de uma análise infantil (ROUDINESCO; PLON, 1998). Com tal manifestação, Freud mostrou que não escolheria nem Anna, nem Melanie, mas, segundo ele, os efeitos da palavra; os efeitos da prática com crianças é que decidiriam pela pertinência e adequação da intervenção mais própria com a infância, onde, pela criança encontrar-se em franca formação, teme-se, mais ainda pelos efeitos de uma antecipação à experiência (GURSKI, 2010).

Em meio a modelos de conexão que se antecipam à experiência, ou ainda que diagnosticam exaustivamente os sujeitos, em uma posição demasiada imaginária, muito frequentemente, algumas abordagens da Psicanálise terminam por serem exauridas do espaço educacional. Ora, não se pode abrir mão de considerar o contexto simbólico apontado por Cifali e Imbert (1999), que, de algum modo, Freud acabou por tangenciar quando introduziu a necessidade de se olhar para o educador e não apenas para a criança, iluminando o que se passa nessa transmissão. Ou seja, Freud, quando aponta para a experiência como termômetro do que teria valor no trabalho com as crianças, não deixou de sublinhar a relevância da transmissão e da ética em detrimento de uma técnica também na clínica com crianças.

\section{Psicanálise e Educação: conexões}

Conforme lembra Lajonquière (2002), a Educação na Viena do século XX tinha na moral e nos bons costumes uma referência, efeitos, é claro, de uma sociedade fortemente marcada pela herança aristocrática. O objetivo maior era educar para o progresso social, aspecto que Freud percebeu na medida em que se desviou de uma aplicabilidade da Psicanálise ligada à moral religiosa, tão presente naquele momento cultural.

Na Conferência XXXIV, Freud (1933/2006) apresenta ainda um meio para que a atuação do educador evite os excessos que os adultos geralmente produzem nas suas relações com os pequenos, justamente por desconhecerem os aspectos próprios do infantil e dos efeitos da transferência. Mas, ele adverte, o educador jamais reprime o que não é possível de ser abafado, qual seja, os desejos inconscientes da criança. Desse modo, Freud (1933/2006, p. 147) aponta que o educador deve conhecer a criança, dar-lhe amor e manter também uma dose de autoridade que permita sua interferência, descobrindo, assim, um "ponto ótimo" para sua aproximação. Deixa-nos, então, a 
pergunta sobre o que se pode fazer com a Educação para que esta realize o máximo e prejudique o mínimo.

Como diz Freud (1913/2012) em Interesses da Psicanálise, o educador deve ter empatia com a alma infantil. Ocorre que os adultos se afastam da sua infância através do recalque, colocando todas as vivências precoces sob o efeito da amnésia que os acomete (FREUD, 1905/2006; 1933/2006). Se a Psicanálise trouxe luz à infância, reconhecendo a sexualidade infantil e mostrando que os primeiros anos da criança estão vinculados com a vida psíquica do adulto, talvez um dos modos de conexão entre os dois campos seja justamente a possibilidade dos pais e docentes experimentarem uma outra relação com o infantil, um laço no qual a singularidade da criança, como sujeito, possa vir a superar a demanda de ilusão por um ideal pedagógico. Ora, nem a escola e, tampouco, o professor podem ser a medida ideal para a criança ou para o jovem, pois, se o forem, estarão desconsiderando um dos operadores mais interessantes para pensar as conexões da Psicanálise com a Educação, o conceito de transferência. Como disse Freud, no texto sobre suicídio (1910/2006, p. 244, grifo nosso): “a escola não deve pretender ser mais do que uma maneira de vida".

Neste breve retorno aos escritos freudianos, relativos à Educação, nos perguntamos se acaso as "pérolas" que Freud tanto visionava em sua aposta de futuro com relação ao laço da Psicanálise com a Educação, não viriam, justamente, do desejo de que as gerações futuras pudessem ler neste enlace algo de "novo", algo de diferente do que até então tinha sido possível para ele e para seus discípulos implicados nesta causa. Assim, sem ambicionarmos nenhum horizonte de filiação pura e dileta da herança do Pai da Psicanálise, buscamos, uma leitura possível das inúmeras conexões que se armam sob o pano de fundo da impossibilidade atávica a estes campos.

\section{Referências}

CIFALI, Mireille; IMBERT, Francis. Freud e a Pedagogia. São Paulo: Loyola, 1999.

BRASIL. Programa de Execução de Medidas Socioeducativas de Internação e Semiliberdade do Rio Grande do Sul (PEMSEIS). Porto Alegre: SDH, 2014.

FREUD, S. Extratos dos documentos redigidos a Fliess. In: . Publicaçoes pré-psicanalíticas e esboços inéditos 1892-1899. Obras Completas. Rio de Janeiro: Imago, 2006. v. 1. Publicado originalmente em 1950.

. Três ensaios sobre a teoria da sexualidade. In: . Obras completas. Rio de Janeiro: Imago, 2006. v. 7. Publicado originalmente em 1905. 
. O esclarecimento sexual das crianças. In: . Obras completas. Rio de Janeiro: Imago, 2006. v. 9. Publicado originalmente em 1907.

. Contribuições para uma discussão acerca do Suicídio. In: . Obras completas. Rio de Janeiro: Imago, 2006. v. 11. Publicado originalmente em 1910.

. A dinâmica da transferência. In: Obras completas. Rio de Janeiro: Imago, 2006. v. 12. Publicado originalmente em 1912.

. O interesse da psicanálise. In: - Obras completas: Totem e Tabu, contribuição à história do movimento psicanalítico e outros textos (1912-1914). São Paulo: Companhia das Letras, 2012. v. 11. Publicado originalmente em 1913.

- Prefácio a O método psicanalítico, de Oskar Pfister. In: . Obras completas. Observações psicanalíticas sobre um caso de paranoia relatado em autobiografia: (“O caso Shreber”), Artigos sobre técnica e outros textos (1911-1913). São Paulo: Companhia das Letras, 2012. v. 10. Publicado originalmente em 1913b.

. A história do movimento psicanalítico. In: . Obras completas. Rio de Janeiro: Imago, 2006. v. 14. Publicado originalmente em 1914.

. Algumas reflexões sobre a psicologia escolar. In: . Obras completas. Rio de Janeiro: Imago, 2006. v. 13. Publicado originalmente em 1914b.

. Além do princípio do prazer. In: Publicado originalmente em 1920. . Obras completas. Rio de Janeiro: Imago, 2006. v. 18.

. Psicologia das massas e análise do eu. In: Obras completas. Psicologia das massas e análise do eu e outros textos (1920-1923). São Paulo: Companhia das Letras, 2012. v. 15. Publicado originalmente em 1921.

. O ego e o id. In: Obras completas. Rio de Janeiro: Imago, 2006. v. 19. Publicado originalmente em 1923.

. A dissolução do complexo de Édipo. In: v. 19. Publicado originalmente em 1924. . Obras completas. Rio de Janeiro: Imago, 2006.

. Prefácio a Juventude Desorientada, de Aichhorn. In: . Obras completas. Rio de Janeiro: Imago, 2006. v. 19. Publicado originalmente em 1925.

. A questão da análise Leiga: conversações com uma pessoa imparcial. In: Obras completas. Rio de Janeiro: Imago, 2006. v. 20. Publicado originalmente em 1926.

. O mal-estar na civilização. In: . Obras completas. Rio de Janeiro: Imago, 2006. v. 21. Publicado originalmente em 1930.

. Novas Conferências Introdutórias de Psicanálise - Conferência XXXIV explicações, aplicações e orientações. In: . Obras completas. Rio de Janeiro: Imago, 2006. v. 12. Publicado originalmente em 1933.

. Esboço de Psicanálise. In: . Obras completas. Rio de Janeiro: Imago, 2006. v. 23. Publicado originalmente em 1940.

FUKS, Betty. Frend e a cultura. Rio de Janeiro: Zahar, 2007. 
GAY, Peter. Uma vida para o nosso tempo. São Paulo: Cia das Letras, 2012.

GURSKI, Roselene. Algumas observações sobre a clínica da infância. Revista da Associação Psicanalítica de Porto Alegre, Porto Alegre, n. 39, p. 90-102, jul./dez. 2010.

KLEIN, M. Inveja e gratidão. Rio de Janeiro: Imago, 1991.

KUPFER, Maria Cristina. Educação para o futuro: psicanálise e educação. 2. ed. São Paulo: Escuta, 2007.

LACAN, J. O seminário, livro 7. A ética da Psicanálise. Rio de Janeiro: Zahar, 2010. Publicado originalmente em 1959-1960.

LAJONQUIÈRE, Leandro de. Sigmund Freud, a educação e as crianças. Estilos da Clínica, v. 7, n. 12, p. 112-129, 2002.

MEZAN, Renato. O tronco e os ramos. São Paulo: Cia das Letras, 2014.

PORGE, Erik. Transmitir a clínica psicanalítica: Freud, Lacan, Hoje. São Paulo: Unicamp, 2009.

ROUDINESCO, Elisabeth; PLON, Michel. Dicionário de psicanálise. Rio de Janeiro: Zahar, 1998.

SCHUR, M. Freud: vida e agonia, uma biografia. Rio de Janeiro: Imago, 1981. v. 1.

VOLTOLINI, Rinaldo. Educação e Psicanálise. Zahar: Rio de Janeiro, 2011. 